\title{
Sexual and reproductive health
} under the Trump presidency: policy change threatens women in the USA and worldwide

\author{
Daniel Grossman
}

Advancing New Standards in Reproductive Health (ANSIRH), Bixby Center for Global Reproductive Health, Department of Obstetrics, Gynecology and Reproductive Sciences, University of California, San Francisco, Oakland, CA, USA:

Daniel.Grossman@UCSF.edu

Received 31 January 2017 Revised 7 February 2017

Accepted 13 February 2017 Published Online First 2 March 2017

\section{CrossMark}

To cite: Grossman D. J Fam Plann Reprod Health Care 2017;43:89-91.
Even before President Trump's inauguration, it was clear that women's sexual and reproductive health (SRH) was going to be a focus of his policy initiatives. Now that he is in office, the impact of these policy changes is beginning to come into focus - and these initiatives affecting abortion, contraception, maternity care and more - are concerning from a medical and public health perspective. The past decade has seen improvements in the use of more effective contraception and a reduction in unintended pregnancy in the USA, ${ }^{1}$ and it is worrisome that Trump's policies could roll back progress on women's health.

One of President Trump's first executive orders after his inauguration was to re-impose the Mexico City Policy, which regulates US funding to foreign nongovernmental organisations. Also known as the Global Gag Rule, this policy prevents organisations that receive United States (US) funding from using any of their financial resources, regardless of source, to provide, inform about or advocate for access to abortion care in their countries. The Trump order appears to have expanded the scope of the Gag Rule, which has been imposed by every Republican president since Ronald Reagan: it now extends beyond funding from the United States Agency for International Development (USAID) to include programmes such as the President's Emergency Plan for AIDS Relief (PEPFAR) and the National Institutes of Health (NIH). If reducing abortion were the aim of this policy, it is not at all clear that it is effective. Data from over a quarter of a million women across 20 nations suggested that the Global Gag Rule was associated with an increase in abortion in sub-Saharan African countries, which may be because affected organisations lost funding for contraceptive supplies. ${ }^{2}$

During the campaign and since his election, President Trump also vowed to appoint justices to the Supreme Court who would overturn Roe $v$. Wade, the landmark 1973 ruling making abortion legal nationwide. At one point he even went so far as to say that women obtaining an abortion if it were illegal in the future would have to be "punished", although he later softened that stance. In nominating Neil Gorsuch to the Supreme Court, Trump appears to have kept his promise. Gorsuch has a troubling record of hostility on women's equality and reproductive rights, having ruled in favour of employers imposing their religious beliefs on employees by denying them access to contraception, and he has been highly critical of abortion jurisprudence.

Despite Trump's statements in support of reversing Roe $v$. Wade, it is unclear that this ruling could be overturned in the near future, even if the new president appoints an additional justice beyond the one to fill the currently open seat. The Court's decision has stood for 44 years and has been reaffirmed in several subsequent rulings, most recently in 2016 in the case of Whole Woman's Health $v$. Hellerstedt, which also provided judicial clarity around what constitutes undue burden on access to abortion care. ${ }^{3}$

But the threat to abortion access in the USA should not be minimised. State legislatures and the US Congress will certainly feel emboldened under the new administration to pass more restrictive legislation. In its first days of session, the US House of Representatives passed HR 7, a bill 
that would deny insurance coverage of abortion care to millions of women. Trump has indicated that he would sign into law a federal ban on abortion after 20 weeks' gestation if such a bill were passed by Congress. Although it is early in most states' legislative sessions, many restrictive bills have been introduced, including some that would ban abortion outright. While litigators have significant judicial precedence to challenge these laws under the framework of Roe, it remains to be seen which restrictive policies, if any, will go into effect.

In the area of contraception, several policy proposals have the potential to limit access severely. Congressional Republicans have expressed a strong desire to prohibit clinics affiliated with Planned Parenthood from receiving federal funding from sources such as Medicaid, the insurance programme for low-income Americans, and Title $\mathrm{X}$, a programme that supports family planning services for low-income individuals. Evidence from Texas, where Planned Parenthood was eliminated from a statefunded fee-for-service family planning programme, shows just how damaging such a policy may be. In the 2 years after these clinics were excluded from the programme, use of long-acting reversible contraceptives declined significantly in Texas, while unintended pregnancy increased. ${ }^{4}$

SRH is also at risk if the Affordable Care Act (ACA), also known as Obamacare, is repealed, as has been promised by Trump and many Congressional Republicans. Under the ACA, women with insurance have been able to access contraception without additional payments (such as insurance deductibles or co-payments), and more women of reproductive age have obtained health coverage. ${ }^{5}$ In the few years that the policy has been in effect, women's out-of-pocket expenditures for contraception have decreased, and contraceptive use appears to have increased. ${ }^{6-8}$ Some researchers have suggested that the recent national decline in abortion in the USA is at least partially related to improvements in contraceptive access and use. ${ }^{9}$ These gains may be reversed if the contraceptive coverage guarantee under the ACA disappeared.

There are other benefits related to SRH under the ACA that would be at risk if the law were repealed. For example, under the ACA, insurance companies may not charge more for plans that include maternity care. With repeal of the law, companies may be able to revert to their biased policies that caused women to pay more for health insurance. Other essential benefits of insurance plans covered by the ACA that may be lost with repeal include well-woman visits with screening for sexually transmitted infections, as well as mental health and substance use disorder services. And perhaps most concerning, low-income individuals in states that have expanded public insurance coverage under Medicaid as part of the ACA may soon find themselves lacking any health insurance if federal funding is withdrawn.
Beyond these specific policies related to SRH, we should not underestimate the potential impact of some of the administration's other policies on health. In his first week in office, Trump imposed severe restrictions on immigration focused on refugees and immigrants from predominantly Muslim countries and put into action his vow to build a wall between the USA and Mexico. These policies create an environment where immigrants - particularly those that are undocumented - feel at high risk for deportation, which in turn may cause them to avoid seeking health care. ${ }^{10}$ In places like California and Texas, where large numbers of undocumented immigrants live, avoidance of care could have adverse effects on maternal and child health. Policies are also anticipated that would allow discrimination against a variety of groups, including women and lesbian, gay and transgender individuals, for religious and moral reasons in ways that could impact access to SRH services.

In these early days of the Trump administration and new Congress, it remains to be seen how many of these proposed policies will really go into effect. Even if executive orders are issued or laws are passed, legal challenges may be brought in the courts that will result in blocking the new policies. Other nations may step in to fill the funding gap if foreign organisations refuse US aid due to the Global Gag Rule. But regardless, it is clear that the US political war on women has reached an all-time apex. In the face of this rhetoric, women's health physicians have a critical role to play: we must be a loud voice in support of evidence-based health care that is unencumbered by political interference.

Competing interests None declared.

Provenance and peer review Commissioned; externally peer reviewed.

\section{REFERENCES}

1 Finer LB, Zolna MR. Declines in unintended pregnancy in the United States, 2008-2011. N Engl J Med 2016;374:843-852.

2 Bendavid E, Avila P, Miller G. United States aid policy and induced abortion in sub-Saharan Africa. Bull World Health Organ 2011;89:873-880C.

3 Grossman D. The use of public health evidence in Whole Woman's Health $v$ Hellerstedt. JAMA Intern Med 2017;177:155-156.

4 Stevenson AJ, Flores-Vazquez IM, Allgeyer RL, et al. Effect of removal of Planned Parenthood from the Texas Women's Health Program. N Engl J Med 2016;374:853-860.

5 Jones RK, Sonfield A. Health insurance coverage among women of reproductive age before and after implementation of the affordable care act. Contraception 2016;93:386-391.

6 Pace LE, Dusetzina SB, Keating NL. Early impact of the affordable care act on oral contraceptive cost sharing, discontinuation, and nonadherence. Health Aff (Millwood) 2016;35:1616-1624. 
7 Law A, Wen L, Lin J, et al. Are women benefiting from the Affordable Care Act? A real-world evaluation of the impact of the Affordable Care Act on out-of-pocket costs for contraceptives. Contraception 2016;93:392-397.

8 Bearak JM, Finer LB, Jerman J, et al. Changes in out-of-pocket costs for hormonal IUDs after implementation of the Affordable Care Act: an analysis of insurance benefit inquiries. Contraception 2016;93:139-144.
9 Jones RK, Jerman J. Abortion incidence and service availability in the United States, 2014. Perspect Sex Reprod Health 2017. Published Online First: 17 January 2017.

10 Raymond-Flesch M, Siemons R, Pourat N, et al. "There is no help out there and if there is, it's really hard to find": a qualitative study of the health concerns and health care access of Latino "DREAMers". J Adolesc Health 2014;55:323-328.

\section{Vacancy — Social Media Editor, JFPRHC}

Journal of Family Planning and Reproductive Health Care (JFPRHC), published by BMJ on behalf of the Faculty of Sexual and Reproductive Health Care in the UK, has an exciting vacancy for an enthusiastic Social Media Editor to drive the journal's web presence worldwide.

$J F P R H C$ is a peer reviewed journal that aims to improve reproductive and sexual health nationally and internationally, and publishes high quality research and information relevant to clinical care, service delivery, training and education in the field of contraception and reproductive/sexual health. More information can be found at jfprhc.bmj.com.

JFPRHC already has a strong readership and offers online features such as a blog, podcasts, Facebook and Twitter. The journal is searching for someone to support the editorial team in improving the journal's visibility and reach via these and other social media, by promoting the journal's content as well as helping its core readership to stay up to date with news and developments in the field.

Candidates should be educated to postgraduate level with knowledge of the journal's subject area. Some experience of science communication and/or digital content management systems such as Twitter, Facebook and WordPress would be preferred, but the main criteria for the successful applicant will be enthusiasm for the subject area, creativity, and an interest in using new technologies to disseminate scientific research. The role would be ideally suited to a junior researcher or practising clinician, and they may be based anywhere in the world.

The Social Media Editor will report directly to the journal's Editor-in-Chief, and will be expected to participate occasionally in the journal's regular editorial meetings (either in person or remotely by telephone or videoconference). This is an unpaid position, but training and support will be provided by BMJ's digital communications team.

To apply, please send your CV and covering letter to Lindsey Fountain, Associate Publisher at BMJ, at Ifountain@bmj.com.

Deadline for applications: 30 July 2017 